This document is the accepted manuscript version of the following article:

Priebe, A., Utke, I., Pethö, L., \& Michler, J. (2019). Application of a gas-injection system during the FIB-TOF-SIMS analysis - Influence of water vapor and fluorine gas on secondary ion signals and sputtering rates. Analytical Chemistry.

\title{
Application of a gas-injection system during the FIB-TOF-SIMS analysis - influence of water vapor and fluorine gas on secondary ion signals and sputtering rates
}

\author{
Agnieszka Priebe*, Ivo Utke, Laszlo Pethö and Johann Michler \\ Empa, Swiss Federal Laboratories for Materials Science and Technology, Laboratory for Mechanics of Materials and \\ Nanostructures, Feuerwerkerstrasse 39, CH-3602 Thun, Switzerland
}

\begin{abstract}
Combining a Gas-Injection System (GIS) with the Focused Ion Beam (FIB) has a broad scope of applications in sample preparation such as protective layer deposition, increasing material sputtering rates and reducing FIB-related artefacts. On the other hand injecting certain specific gases during a Time-of-Flight Secondary Ion Mass Spectrometry (TOF-SIMS) analysis can significantly increase element ionization probability and, therefore, improve the quality of 3D representation of a sample elemental structure. In this work, for the first time the potential of GIS for enhancing secondary ion signals acquired using a TOF detector incorporated into a commercial Ga ${ }^{+}$FIB-SEM (Focused Ion Beam combined with Scanning Electron Microscope) instrument is presented. The depth profiles of pure metals (thin films of $\mathrm{Cu}, \mathrm{Zr}, \mathrm{Ag}$ and $\mathrm{W}$ with the thickness in the order of $100 \mathrm{~nm}$ ) were acquired at ambient vacuum conditions as well as under an exposure to water and fluorine gases. The influence of supplementary gases on the ion yields and sputtering rates were studied. Simulations were performed to assess the local gas pressure at the location of FIB-TOF-SIMS analysis. The highest enhancement of ionization probability was achieved in the case of the Cu thin film (10 times during water co-injection and 510 times when using a fluorine gas). Regarding the sputtering rates, the response of $\mathrm{Zr}$ to effect of the gases was the strongest. Comparing to a standard background pressure measurements, this thin film was milled around 6 times faster under the exposure to a water vapor and over 2 times faster when fluorine gas was supplied.
\end{abstract}

\begin{abstract}
A Gas-Injection System (GIS) is a well-known solution ${ }^{1-3}$ to be combined with Focused Ion Beam (FIB) ${ }^{4}$ for extending its nanomachining capabilities, enabling ion beam-assisted deposition and, therefore, improving a sample preparation process. Among numerous applications, it is commonly used during a sample lift-out (for X-ray computed nano-tomography experiments ${ }^{5-7}$ and lamellae preparation for transmission electron microscopy ${ }^{8}$ ), depositing protective layers (which do not only prevent a sensitive sample surface from destruction but can also decrease charging effects during FIB sputtering), increasing milling rates ${ }^{9,10}$, reducing FIB-induced artefacts (such as curtain effect ${ }^{11,12}$ or material re-deposition ${ }^{13}$ ) and direct writing of the three-dimensional functional nano-devices ${ }^{14-19}$. On the other hand, delivering certain gases to sample proximity during a Time-Of-Flight Secondary Ion Mass Spectrometry (TOF-SIMS) ${ }^{20,21}$ analysis has a beneficial effect on ionization probability and, thus, a signal enhancement in the positive ${ }^{6,22-}$ 27 and negative ${ }^{28-33}$ ion detection modes. This is particularly important in the case of weakly ionizing elements and when the ionization process efficiency is hampered due to so-called matrix effect, i.e. the impact of neighbouring elements on the ion yields of the other elements.
\end{abstract}

In this work, we study the influence of supplementary gases (water vapour and fluorine gas) simultaneously co-injected close to the sample surface during a TOF-SIMS elemental analysis with mono-isotopic ${ }^{69} \mathrm{Ga}^{+}$bombardment on positive secondary ion signals of pure metals such as $\mathrm{Cu}, \mathrm{Zr}$, Ag and $\mathrm{W}$. These elements were chosen due to the fact that they can be used for fabricating novel type of amorphous Bulk Metallic Glasses $^{34-38}$ (BMG), i.e. ZrCuAg, as well as BMG-based nanocomposites, i.e. $\mathrm{ZrCuAg}+\mathrm{W}_{\mathrm{np}}$ (np denotes nanoparticles). The data was acquired using a TOF incorporated as an add-on to a dual beam FIB-SEM (Scanning Electron Microscope) instrument with an integrated five-nozzle GIS. The local gas pressure at the FIB-TOF-SIMS analysis region was simulated.

\section{EXPERIMENTAL}

Four 1-element-thin films of metals ( $\mathrm{Cu}, \mathrm{Zr}, \mathrm{Ag}$ and $\mathrm{W}$ ) were deposited on a $<100>$ single crystal Si substrate using the Physical Vapour Deposition (PVD) technique ${ }^{39}$. 99.99\% purity $\mathrm{Cu}$ and $\mathrm{W}$ solid targets from EVOCHEM GmbH (Offenbach am Main, Germany) and 99.9\% purity $\mathrm{Zr}$ and $\mathrm{Ag}$ solid targets from Testbourne Ltd (Hampshire, England) were used in a 3"' sputter magnetron from MANTIS Deposition Ltd (Oxfordshire, United Kingdom) under conditions specified in Table S1 (in Supplementary Information). The thickness of thin films $h$ was measured on the sample cross-sections using $\operatorname{SEM}\left(h_{C u}=119 \mathrm{~nm}, h_{\mathrm{Zr}}=143 \mathrm{~nm}, h_{A g}=213 \mathrm{~nm}, h_{W}=74 \mathrm{~nm}\right)$. The thin films were chosen for these studies as they have an advantage over bulk samples regarding the assessment of the amount of sputtered material which is crucial for calculating the enhancement of secondary ion signals. Since in most cases a moment of reaching an interface with a substrate can be easily distinguished from the TOF-SIMS depth profiles and the film thickness is known, SEM or AFM (Atomic Force Microscope ${ }^{40}$ ) measurements after the FIB-TOF-SIMS analysis are not necessarily required (in contrast to the bulk materials) for measuring the depth of 


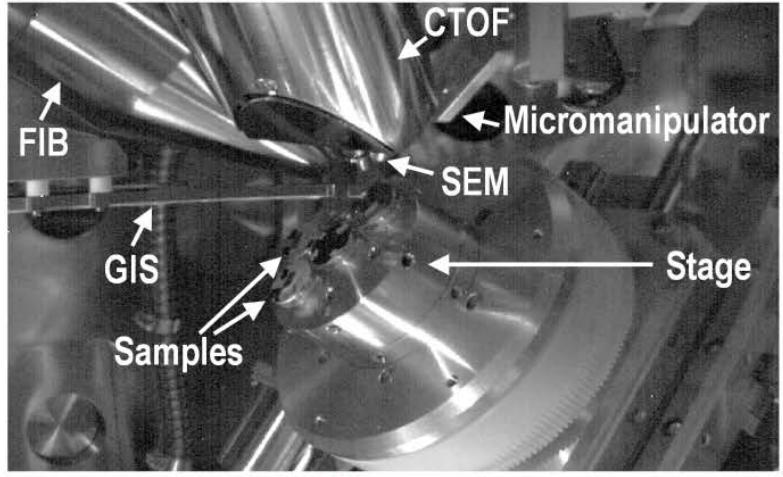

a)

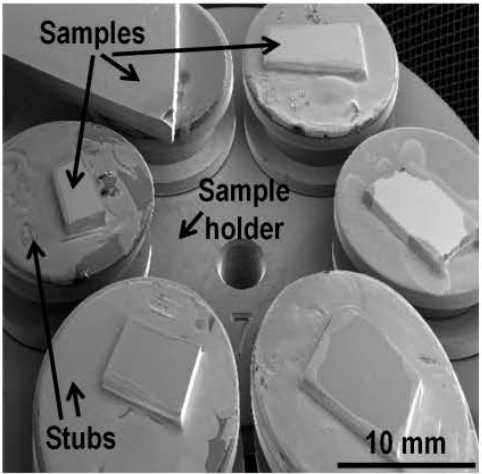

b)

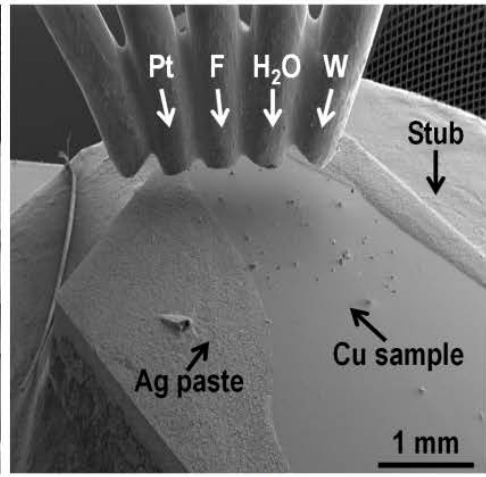

c)

Figure 1. Interior of the analytical chamber, a) orientation of beam columns, detectors and the samples (the image was taken with an optical camera) b) configuration of samples on the sample holder (SEM image), b) 5-line GIS location with respect to the sample surface - in this study, water and fluorine nozzles were used (SEM image).

milled material. These first GIS+FIB-TOF-SIMS studies were performed on pure metals to separate the gas-induced changes in ion signals from the matrix effect and potential mass interference between sample components that can appear when using more complex materials. All samples were coated with $5 \mathrm{~nm} \mathrm{Au}$ layer prior the TOF-SIMS experiments to prevent surface charging during the FIB sputtering.

The experimental setup (Figure 1a) consisted of a dual beam FIB-SEM instrument Lyra3 from Tescan (Brno, the Czech Republic) with an integrated five-line GIS and an incorporated Compact TOF (CTOF) ${ }^{41,42}$ from TOFWERK (Thun, Switzerland). A sample surface was bombarded with a mono-isotopic ${ }^{69} \mathrm{Ga}^{+}$ion beam (used for both, the sputtering and the analysis) at $20 \mathrm{keV}$ energy and 100-120 pA ion current. A $100 \mu \mathrm{m}$ FIB aperture was applied. The sample was mounted normal with respect to the FIB axis and at the cross-point between the ion and electron beams. The data was acquired with $16 \mu$ s dwell time per pixel, $512 \times 512$ pixel resolution (which corresponds to a $19.5 \mathrm{~nm}$ pixel size) and $2 \times 2$ pixel binning from a $10 \mu \mathrm{m} \times 10 \mu \mathrm{m}$ area. In order to avoid an influence of crater wall artefacts (that can mainly result from a material redeposition) the Region-Of-Interest (ROI) for generating TOFSIMS depth profiles was limited to the central $5 \mu \mathrm{m} \times 5 \mu \mathrm{m}$. A continuous flow of gas, either water vapour (obtained from an $\mathrm{MgSO}_{4} \cdot 7 \mathrm{H}_{2} \mathrm{O}$ precursor) or fluorine (obtained from $\mathrm{XeF}_{2}$ precursor) was simultaneously delivered by GIS to the sample surface during the FIB-TOF-SIMS measurements. The nominal GIS work position is around $150 \mu \mathrm{m}$ above the sample and at $70^{\circ}$ angle with respect to the substrate surface (i.e. $20^{\circ}$ angle between the GIS axis and the substrate normal as presented in Figure S1 in Supporting Information).

Experiments with water and fluorine were conducted on two separate sets of samples composed of $\mathrm{Cu}, \mathrm{Zr}$, Ag and $\mathrm{W}$ thin films (Figure $1 \mathrm{~b}-\mathrm{c}$ ) to prevent a potential impact of water vapour or fluorine gas residuals on the ionization process of another one. The corresponding samples were obtained from large wafers on which the thin films were deposited (i.e. from single PVD batches) which has allowed for reducing the effect of material composition variations.

For each gas type a series of measurements were performed in the following regimes: 1 ) the chamber was pumped down to a background pressure of $6.7 \cdot 10^{-6} \mathrm{mbar}$ and no gas was injected during the analysis (Reference 1), 2) no gas was injected during the analysis of a particular sample but the sample was previously affected by the gas delivered to another sample mounted in the vacuum chamber (Reference 2), 3) the gas was injected directly in the proximity of the sample surface. Three measurements were done to verify reproducibility of the gas influence. The operating gas pressure of $8.4 \cdot 10^{-6}$ mbar was measured in the case of water vapour and $1.0 \cdot 10^{-5} \mathrm{mbar}$ in the case of fluorine gas. Additionally, for the Zr sample case 4) was considered when a GIS valve was opened but GIS was located at the home position (relatively far away from the sample surface, i.e. around $12 \mathrm{~mm}$, measured in the horizontal plane, from the FIB column). This has allowed for the verification on whether a reduced amount of fluorine can change the efficiency of element ionization.

The TOF-SIMS data was acquired and processed using TOF-SIMS Explorer version 1.4.0.0. The mass-calibration was performed using a primary ion beam ${ }^{69} \mathrm{Ga}^{+}$signal, ${ }^{28} \mathrm{Si}^{+}$substrate signal and a dominant isotope signal of a thin film.

\section{SIMULATIONS}

In order to assess the local pressures at the FIB-TOF-SIMS ROIs the Empa freeware GIS simulator ${ }^{43-45}$ was used. The implemented spatial arrangement of FIB, GIS and the sample is presented in Figure S1a (in Supporting Information). GIS nozzles were located at the angle of $70^{\circ}$ with respect to the sample surface and around $150 \mu \mathrm{m}$ above it. FIB scanned in the direction from the left to the right staying in the middle of each pixel for a given time (i.e. $16 \mu$ s). The Knudsen numbers (i.e. a ratio of molecular mean free path to the macroscopic length scale ${ }^{46}$ ), $K n$, as well as the total gas flux at the GIS nozzle exit were calculated based on the pressure measurements during the GIS operation with water vapour or fluorine gas and the chamber background pressure. In the simulations, the value of $K n=4.5$ was used as it is representative for both molecule species $\left(K n_{\text {water }}=5.3\right.$ and $\left.K n_{\text {fluorine }}=4.2\right)$ giving the water local pressure of $3 \cdot 10^{-3}$ mbar and the local fluorine pressure of $6 \cdot 10^{-3}$ mbar at the FIB-TOF-SIMS areas. For the case of GIS position at home (around $11 \mathrm{~mm}$ away from the substrate), the local pressure values of $1 \cdot 10^{-5} \mathrm{mbar}$ and $2 \cdot 10^{-5}$ mbar were obtained, respectively. These values are only slightly higher than the operating vacuum chamber pressure. The gas precursor distribution is shown in Figure S1b (in Supporting Information). The colour code denotes the magnitude of gas flux $J$ at the substrate with respect to the total flux $J_{\text {tot }}$ delivered to the exit of the GIS nozzle. The simulations indicate that 5-7 times higher gas flux can be supplied to the 
TOF-SIMS ROI if the GIS nozzle is inserted closer to the FIB. However, it has to be kept in mind that such configuration can potentially affect the ion extraction optics.

\section{RESULTS AND DISCUSSION}

\section{Water vapour-assisted FIB-TOF-SIMS}

TOF-SIMS depth profiles of $\mathrm{Cu}, \mathrm{Zr}, \mathrm{Ag}$ and $\mathrm{W}$ thin films are presented in Figure 2. Since primary beam current varied between $100 \mathrm{pA}$ and $120 \mathrm{pA}$ from each experiment to the other, the data was normalized to an impacting $1 \mathrm{pA}$ beam. The magnitude of the obtained TOF-SIMS signal is individual for each element and is determined by its ionisation probability. In the instrumental setup which was used in these studies the CTOF detector was designed to fit into an existing FIB/SEM. Therefore, the ion collection efficiency is around 2 orders of magnitude lower than in the case of a dedicated TOF-SIMS instrument (for example TOF.SIMS ${ }^{5}$ ). Figure 2 a1a4 show signals acquired for elements forming the thin films $\left({ }^{63} \mathrm{Cu}^{+},{ }^{90} \mathrm{Zr}^{+},{ }^{107} \mathrm{Ag}^{+}\right.$and ${ }^{184} \mathrm{~W}^{+}$, respectively) whilst Figure 2 b1-b4 show the corresponding ${ }^{28} \mathrm{Si}^{+}$signals of the substrate. In the case of ${ }^{63} \mathrm{Cu}^{+}$(Figure 2 a1-b1), a sharp signal peak within first 5 frames of the sputtering process was observed. This most likely has resulted from sample surface oxidation at ambient atmosphere prior to the TOF-SIMS experiments. In the plateau of all ${ }^{63} \mathrm{Cu}^{+}$signals (frames 5-100), an injection of the water vapour has caused signal increase by a factor of around 15. A very similar result was obtained in the case of Reference 2 when the gas was not directly delivered to the sample surface but was present in the analytical chamber before (used for another sample). Regarding ${ }^{28} \mathrm{Si}^{+}$, the situation is quite different - Reference 2 signal is 13 times higher than Reference 1 signal but signals acquired with water vapour are already 100 times higher (at frame 220). This shows much stronger Si response to water vapour whilst $\mathrm{Cu}$ seems to be less sensitive to the quantity of provided water gas.

The ${ }^{90} \mathrm{Zr}^{+}$depth profiles (Figure 2 a2) indicate that for this material the use of lower gas concentration in the proximity of the sample surface is preferential for enhancing secondary ion yields. Reference 2 signal was around 3 times higher than Reference 1 signal whilst signals obtained with water vapour are lower by a factor of 2 (between frames 65 and 450). This effect is even more evident in the case of substrate signal (Figure 2 b2) where the Reference 2 peak value of ${ }^{28} \mathrm{Si}^{+}$(frame 535 ) is over 5 times higher than the one of Reference 1 and 4 times greater than the signals measured with the water vapour (in the region behind the thin film-substrate interface, i.e. around frame 100).

${ }^{107} \mathrm{Ag}^{+}$results (Figure $2 \mathrm{a} 3$ ) show a similar response to the water vapour as ${ }^{63} \mathrm{Cu}^{+}$. However, here the ionization process was in general less efficient, i.e. by one order of magnitude, when comparing the measurements conducted with and without water vapour. The water vapour (injected directly on the sample surface as well as used on another sample, i.e. Reference 2) has enhanced ${ }^{107} \mathrm{Ag}^{+}$signal approximately by a factor of 10 (around frame 100). Regarding ${ }^{28} \mathrm{Si}^{+}$substrate (Figure 2 b3), Reference 2 measurement has given almost 6 times higher signal than Reference 1 and the direct impact of water on the sample resulted in signal enhancement by a factor of 15 (around frame 350). In the case of $\mathrm{W}$ thin film (Figure 2 a4b4), concerning the peak values, a signal increase of up to 2 was obtained for ${ }^{184} \mathrm{~W}^{+}$and an increase by a factor of almost 4 for ${ }^{28} \mathrm{Si}^{+}$.

Based on TOF-SIMS depth profile shapes, the element response to surface oxidation can be judged. Figure 2 a1-d1 indicate that $\mathrm{Cu}$ and $\mathrm{Ag}$ are much more sensitive to the presence of oxygen than $\mathrm{Zr}$ and $\mathrm{W}$ giving strong peak signals within the first several frames and then drastically dropping (by a factor of 15 and 16 for the Reference 1 measurements of $\mathrm{Cu}$ and Ag, respectively and by a factor of 3.4 and 2.9 in the case of corresponding values acquired with the presence of water vapour). Comparison of ${ }^{28} \mathrm{Si}^{+}$signals in Figure 2 b1-b4 shows significant differences both in the signal distribution shape as well as in the signal magnitude varying from a sample to sample. This results most probably from an additive effect of the supplementary gas in the vacuum chamber as well as the presence of thin film material fragments (coming most likely from the preferential sputtering) around the substrate, i.e. the matrix effect.

The Reference 2 signals can be as high as TOF-SIMS signals obtained with the presence of water vapour (in the case of $\mathrm{Cu}, \mathrm{Ag}$ and $\mathrm{W}$ samples) or even higher (Zr sample). Moreover, the substrate signals are also significantly affected. Although the exposure of only the upper-most part of the sample surface can be expected due to the prior gas injection, also secondary ion signal modifications of the deeper buried parts (including the sample substrate) are observed. This can be explained by the residual water vapour still present in the vacuum chamber (i.e. not being efficiently evacuated by the vacuum pumps after closing GIS nozzles). Besides that, there can be a very narrow window of the amount of gas that provides the maximum secondary ion yield enhancement. This means that smaller quantity of the supplementary gas can lead to better enhancement of ionisation process than in the case when a sample surface is saturated with the gas. Such a phenomenon is valid for example in the case of Cs gas $^{28-30}$ used for improving negative ion yields.

TOF-SIMS signals normalized to the value of 1 are given in Figure S2 (in Supporting Information) for better visualisation of distribution shapes. Plots in a1-d1 refer to Reference 1 measurements and plots in a2-d2 show the average values of the three measurements (shown in Figure 2) taken when exposing the sample surfaces to the direct flow of water vapour equivalent to $3 \cdot 10^{-3}$ mbar local water pressure or around $10^{3}$ monolayers of water per second. In most cases, the combination of the thin film element signal with the substrate signal has allowed the interface location to be assessed. In the case when a distinct decrease of the thin film signal was observed together with a sudden increase of the substrate signal, the intersection of these two denoted the location of the interface (Figure S2 b1, b2, d1, d2). Otherwise, when only ${ }^{28} \mathrm{Si}^{+}$signal rise has occurred (Figure S2 a1, a2, c1, c2), the interface location was assigned to the moment of reaching $50 \%$ of its maximum value. Based on that the time-integrated (from the beginning of the sputtering process on the sample surface, $t_{\text {surface, }}$, to the moment of reaching the interface with 


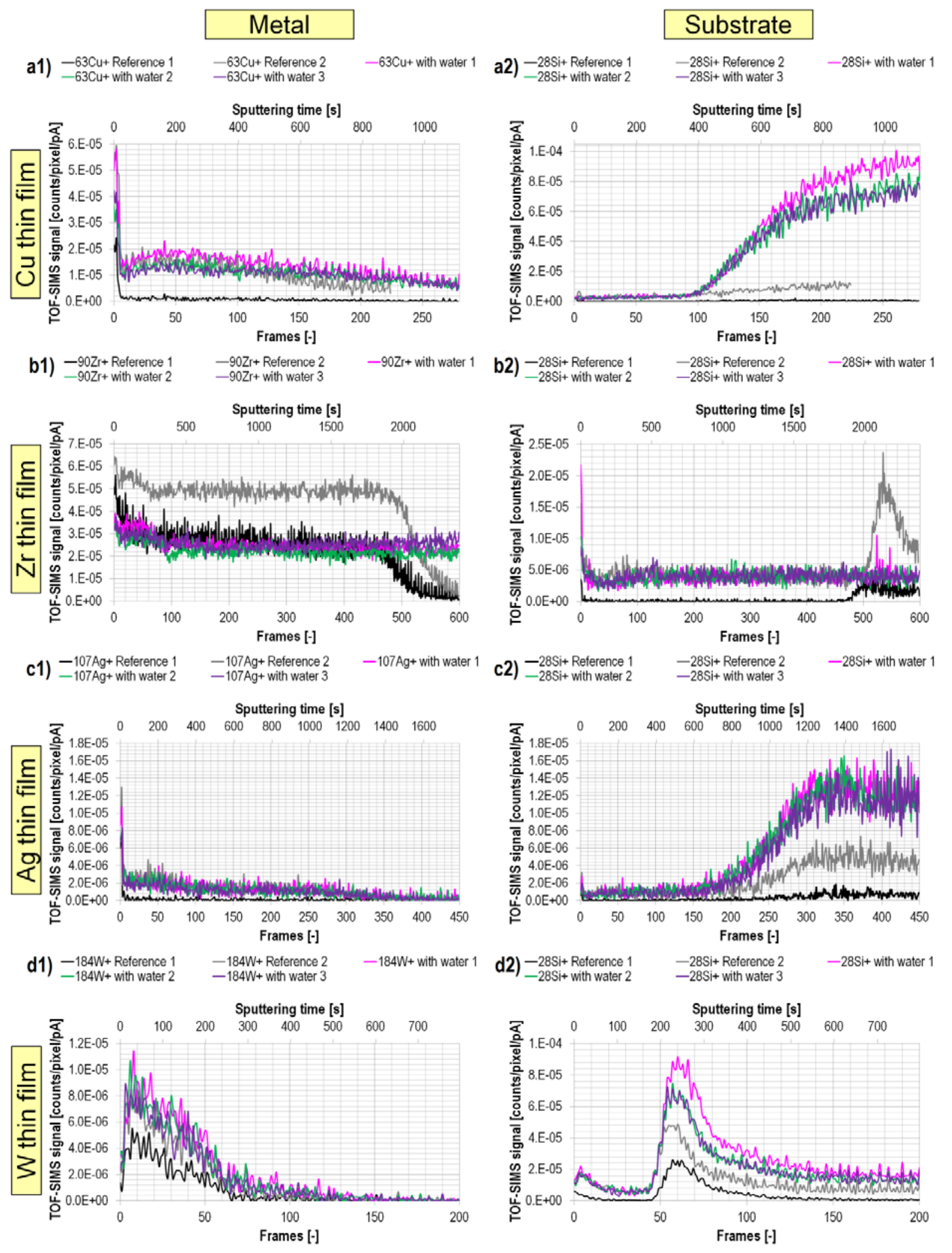

Figure 2. TOF-SIMS depth profiles of ${ }^{69} \mathrm{Cu}^{+},{ }^{90} \mathrm{Zr}^{+},{ }^{107} \mathrm{Ag}^{+}$and ${ }^{184} \mathrm{~W}^{+}$(a1-d1) and corresponding ${ }^{28} \mathrm{Si}^{+}$substrate signals (a2-d2) acquired without and with the presences of water vapour. For better comparison the data was normalized to 1 pA of the impacting primary beam current. Reference 1 signals correspond to measurements performed in standard vacuum conditions (without any gases). Reference 2 signals were acquired with the closed GIS valve but samples were exposed to the supplementary gas prior the measurements. 
Table 1. Summary of the gas enhancement factors for TOF-SIMS (GAE $\left.E_{\text {TOF-SIMS_water }}\right)$ and $\mathrm{Ga}^{+}$sputter rates $\left(G A E_{S P_{-} \text {water }}\right)$ with water vapour. The TOF-SIMS signals were integrated over the thin film thickness during the experiments without $\left(S_{\text {reference }}\right)$ and with $\left(S_{\text {water }}\right)$ water over time until the interface was reached $\left(t_{\text {interface }}\right)$.

\begin{tabular}{|c|c|c|c|c|c|c|}
\hline & \multicolumn{2}{|c|}{$\begin{array}{l}\text { Moment of reaching the interface } \\
\text { [frames] }\end{array}$} & \multicolumn{2}{|c|}{$\begin{array}{l}\text { Integrated TOF-SIMS signal in a thin } \\
\text { film [counts/px/pA] }\end{array}$} & \multirow{2}{*}{$\begin{array}{c}G A E_{\text {TOF-SIMS_water }} \\
{[-]}\end{array}$} & \multirow{2}{*}{$\underset{[-]}{G A E_{S P \text { water }}}$} \\
\hline & $t_{\text {interface_reference }}$ & $t_{\text {interface_water }}$ & $S_{\text {reference }}$ & $S_{\text {water }}$ & & \\
\hline${ }^{63} \mathrm{Cu}^{+}$ & $136 \pm 20$ & $148 \pm 6$ & $(2.1 \pm 0.2) \times 10^{-4}$ & $(2.1 \pm 0.1) \times 10^{-3}$ & $(10.0 \pm 2)$ & $(0.9 \pm 0.2)$ \\
\hline${ }^{90} \mathrm{Zr}^{+}$ & $482 \pm 10$ & $78 \pm 20$ & $(1.3 \pm 0.2) \times 10^{-2}$ & $(2.4 \pm 0.6) \times 10^{-3}$ & $(0.18 \pm 0.08)$ & $(6 \pm 2)$ \\
\hline${ }^{107} \mathrm{Ag}^{+}$ & $305 \pm 25$ & $262 \pm 14$ & $(6.2 \pm 0.4) \times 10^{-5}$ & $(4.2 \pm 0.2) \times 10^{-4}$ & $(6.7 \pm 0.8)$ & $(1.2 \pm 0.2)$ \\
\hline${ }^{184} \mathrm{~W}^{+}$ & $49 \pm 3$ & $51 \pm 2$ & $(1.5 \pm 0.1) \times 10^{-4}$ & $(3.2 \pm 0.2) \times 10^{-4}$ & $(2.1 \pm 0.3)$ & $(1.0 \pm 0.1)$ \\
\hline
\end{tabular}

the substrate, $t_{\text {interface }}$ ) signals from the thin films were calculated using the following equation:

$$
S_{T O F-S I M, t o t a l}=\int_{t_{\text {surface }}=0}^{t_{\text {interface }}} S_{\text {TOF-SIMS }}(t) d t .
$$

Assuming that the uncertainty of estimating the location of the interface (and thus the number of detected secondary ions) as well as the thin film thickness variations are negligible, the gas enhancement factor for ionization, and therefore for the TOF-SIMS signal, GAE $E_{\text {TOF-SIMS }}$, can be defined as the ratio of the total element TOF-SIMS signal obtained when acting on a sample with an additional gas, $S_{g a s}$, to the total element TOFSIMS signal of the material measured at the background pressure, $S_{\text {reference: }}$ :

$$
G A E_{\text {TOF-SIMS }}=\frac{s_{\text {gas }}}{s_{\text {reference }}} .
$$

This is equivalent to the enhancement of useful yields which are defined as ratios between a number of detected ions and a number of sputtered atoms of that specific element. Since useful yields are not characteristic for a chemical element as ionization probability can vary due to the matrix effect and, in addition, they depend on detector parameters ${ }^{47-49}$, it seems more reasonable to compare the ratios of useful yields calculated at different experimental conditions for a specific element instead of using the absolute values.

The results are summarized in Table 1 (the methods used to assess the errors are discussed in the following section Error estimations). Overall, the water vapour has enhanced the ionization probability (indirectly measured with the TOF-SIMS signals) by an order of magnitude in the case of $\mathrm{Cu}$ and $\mathrm{Ag}$. A weaker effect was observed for $\mathrm{W}$ and a reverse tendency has occurred for Zr, i.e. the signal has decreased by a factor of 5 . In the literature, the only results dedicated to the application of water vapour for a TOF-SIMS analysis concern organic molecules ${ }^{25,26}$. A water cluster primary beam during TOF-SIMS analysis on bio-compounds was reported in ${ }^{22-24}$. However, to our knowledge no studies on metals were performed using the combined FIB-TOF-SIMS technique with water vapour based GIS. Therefore, values of GAE $E_{\text {TOF-SIMS_water }}$ for $\mathrm{Cu}, \mathrm{Zr}, \mathrm{Ag}$ and $\mathrm{W}$ are provided for the first time. The injected gas has also affected the sputtering rates of the thin films. Gas enhancement factor for $\mathrm{Ga}^{+}$sputter rate, $G A E_{S P}$, is defined by the amount of material sputtered at a given time. Since the thickness of the metal thin film as well as the sputter area are the same for the measurements conducted without and with a supplementary gas, $G A E_{S P}$ can be expressed as the ratio of the time needed to reach an interface with Si substrate at the background pressure to the corresponding time needed when the gas is supplied:

$$
G A E_{S P}=\frac{t_{\text {interface_reference }}}{t_{\text {interface_gas }}} .
$$

The obtained values of $G A E_{S P}$ are also given in Table $1 . \mathrm{Zr}$ and $\mathrm{Ag}$ layers were milled faster but on the other hand $\mathrm{Cu}$ was sputtered by $8 \%$ slower when comparing it to the case without water vapour. Only for $\mathrm{W}$ no difference in milling efficiency was observed. These results can be explained with the fundamental concept of gas enhanced milling. The chemically nonreactive physisorbed gas molecules (here $\mathrm{H}_{2} \mathrm{O}$ or $\mathrm{XeF}_{2}$ ) are dissociated by excited surface atoms ${ }^{50,51}$ and secondary electrons ${ }^{14}$ generated by the primary ion beam impinging on the sample surface. The fragments produced in the dissociation process are chemically reactive and affect the surface atoms. In consequence, the reaction product has a different surface binding energy than compared to the initial sample element and therefore its sputter rate changes as well. The values of $G A E_{S P}$ reported in literature ${ }^{17}$ can reach few tens of values obtained in the case of a non-chemistry supported milling. In general, binding energies of ion-impact amorphized (i.e. dislocated) and Ga-implanted surfaces are difficult to access. However, the milling rates are increased when a surface reaction compound is volatile whilst they remain unchanged or lower (than in the case when a gas was not supplied) if the reaction product is not volatile. These mechanisms imply the presence of reactive $\mathrm{H}^{+}, \mathrm{O}^{-}$and $\mathrm{OH}^{-}$radicals during the water vapour assisted FIB milling process and therefore lead to the formation of metal ( $M^{x}$, where $x$ is a valence) compounds such as hydrides, $H_{x} M$, metal oxides, $M O_{x}$ and hydroxides, $M(\mathrm{OH})_{x}$ :

$$
M^{x}+H_{2} O \stackrel{F I B}{\longrightarrow} H_{x} M, M O_{x}, M(O H)_{x} .
$$

An application of water vapour for etch rate enhancement of metals has never been investigated to our best knowledge and our results given in Table 1 represent the first published values.

\section{Fluorine gas-assisted FIB-TOF-SIMS}

Following the methodology from the previous section, the influence of fluorine on the TOF-SIMS signals of ${ }^{63} \mathrm{Cu}^{+},{ }^{90} \mathrm{Zr}^{+}$, ${ }^{107} \mathrm{Ag}^{+}$and ${ }^{184} \mathrm{~W}^{+}$was studied. Figure 3 a1-d1 present the depth profiles of thin film elements acquired with and without fluorine gas normalized to an acting $1 \mathrm{pA}$ ion current and Figure 3 a2-d2 show the corresponding ${ }^{28} \mathrm{Si}^{+}$substrate signals. In the case of $\mathrm{Cu}$ sample, the fluorine gas has enhanced the 

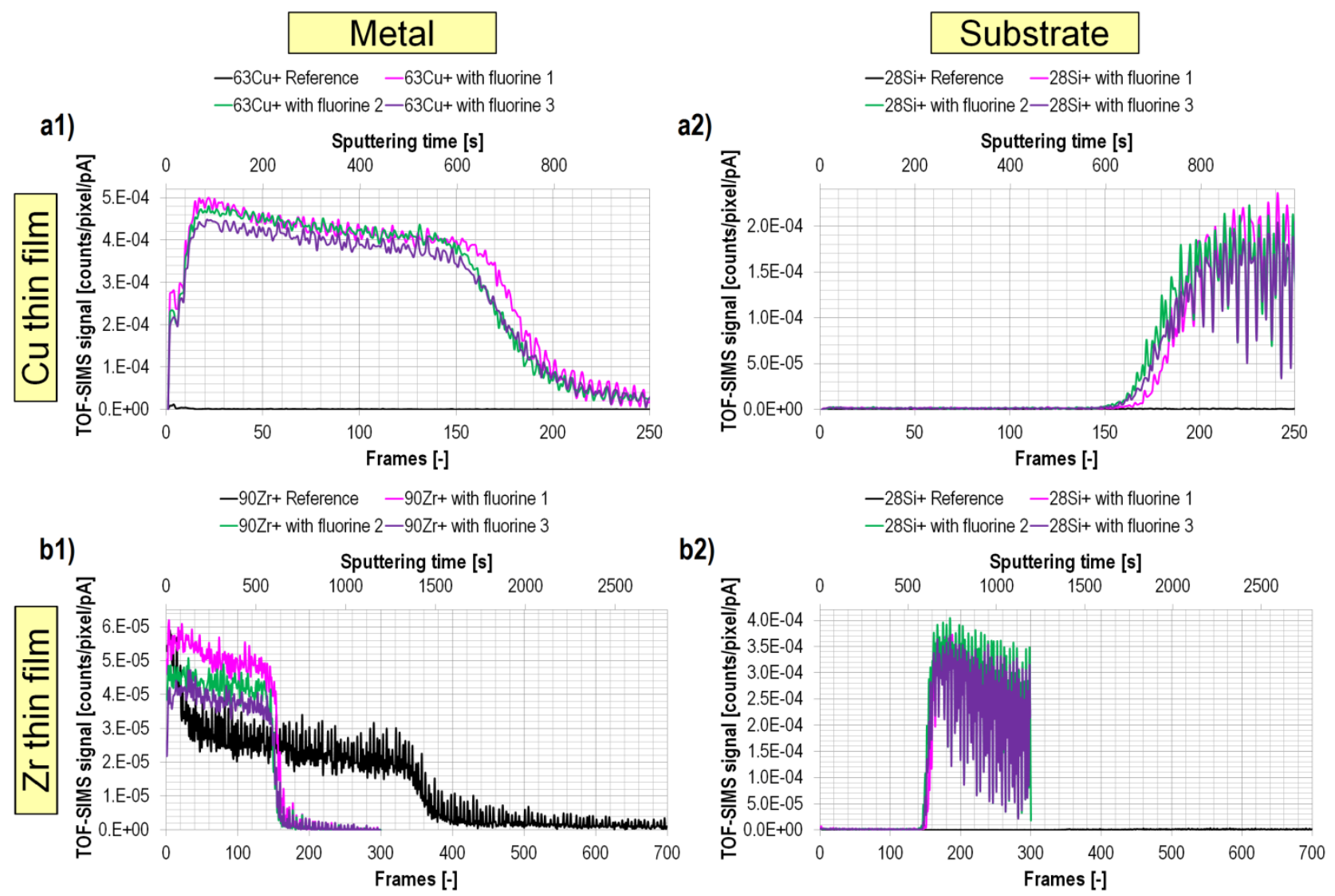

b2)

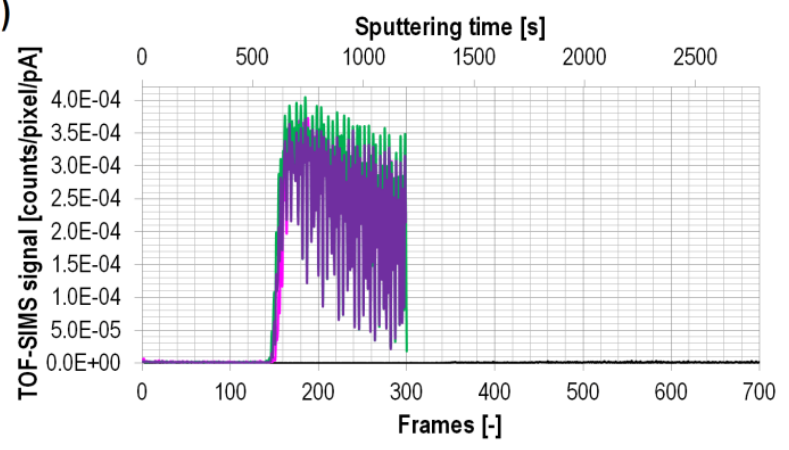

c1)

$-107 \mathrm{Ag}+$ Reference $\quad-107 \mathrm{Ag}+$ with fluorine 1

$-107 \mathrm{Ag}+$ with fluorine $2-107 \mathrm{Ag}+$ with fluorine 3

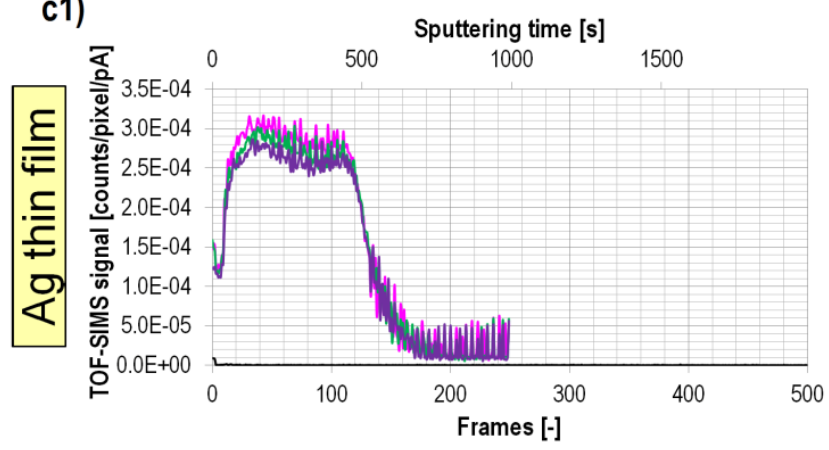

c2)

$-28 \mathrm{Si}+$ Reference $\quad-28 \mathrm{Si}+$ with fluorine 1
$-28 \mathrm{Si}+$ with fluorine $2-28 \mathrm{Si}+$ with fluorine 3

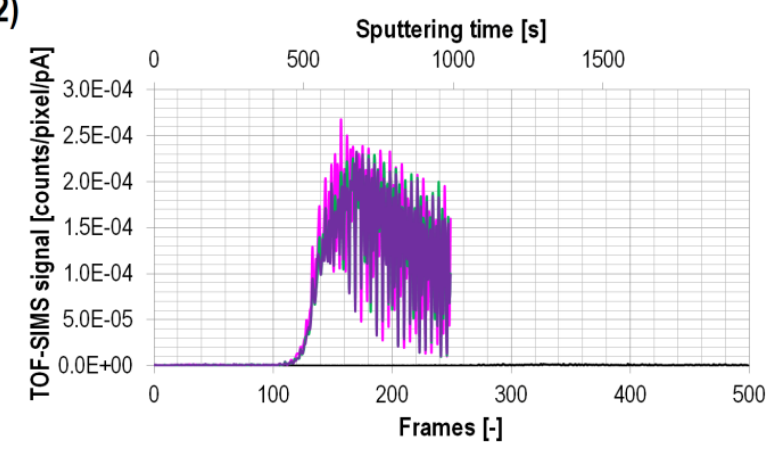

$-184 \mathrm{~W}+$ Reference $\quad-184 \mathrm{~W}+$ with fluorine 1

d1)

$-184 \mathrm{~W}+$ with fluorine $2-184 \mathrm{~W}+$ with fluorine 3

\section{d2)}
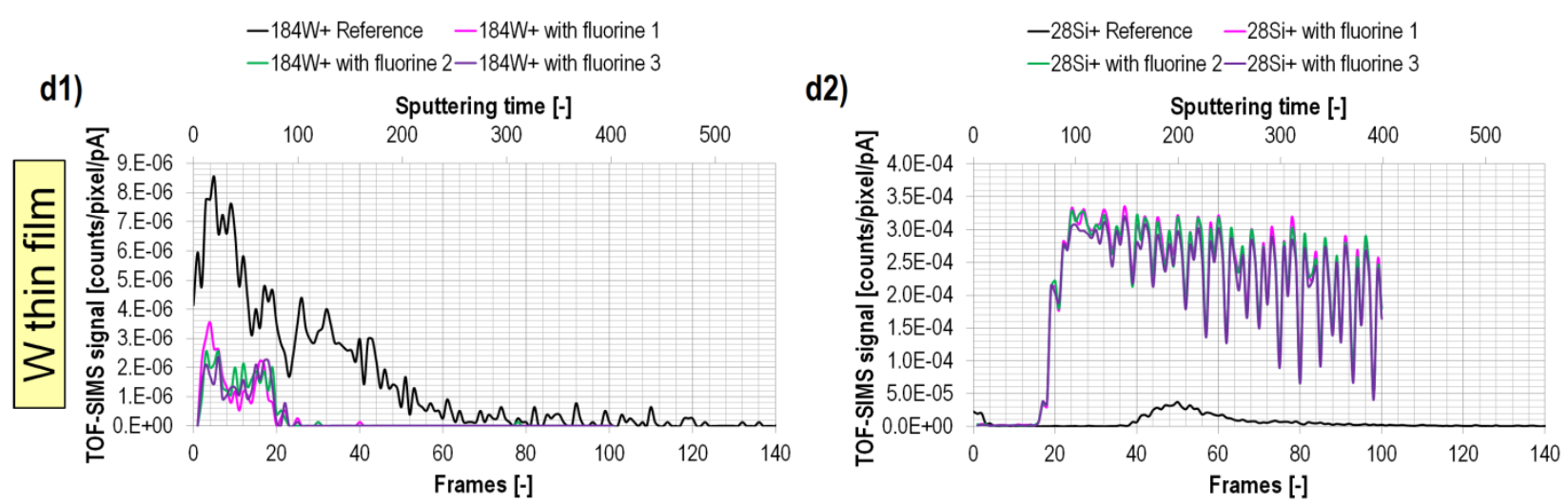

Figure 3. TOF-SIMS depth profiles of ${ }^{69} \mathrm{Cu}^{+},{ }^{90} \mathrm{Zr}^{+},{ }^{107} \mathrm{Ag}^{+}$and ${ }^{184} \mathrm{~W}^{+}$(a1-d1) and corresponding ${ }^{28} \mathrm{Si}^{+}$substrate signals (a2-d2) acquired without and with the presences of fluorine gas. For better comparison the data was normalized to $1 \mathrm{pA}$ of the impacting primary beam current. Reference 1 signals correspond to measurements performed in standard vacuum conditions (without any gases). 
Table 2. Summary of the gas enhancement factors for TOF-SIMS (GAE $\left.E_{\text {TOF-SIMS_fluorine }}\right)$ and $\mathrm{Ga}^{+}$sputter rates $\left(G A E_{\text {SP_fluorine }_{2}}\right)$ with fluorine gas. The TOF-SIMS signals were integrated over the thin film thickness during the experiments without $\left(S_{\text {refer- }}\right.$ ence) and with ( $\left.S_{\text {fluorine }}\right)$ fluorine over time until the interface was reached $\left(t_{\text {interface }}\right)$.

\begin{tabular}{|c|c|c|c|c|c|c|}
\hline & \multicolumn{2}{|c|}{$\begin{array}{l}\text { Moment of reaching the interface } \\
\text { [frames] }\end{array}$} & \multicolumn{2}{|c|}{$\begin{array}{l}\text { Integrated TOF-SIMS signal in a thin } \\
\quad \text { film [counts/px/pA] }\end{array}$} & \multirow{2}{*}{$\begin{array}{c}G A E_{\text {TOF-SIMS_fluorine }} \\
{[-]}\end{array}$} & \multirow{2}{*}{$\begin{array}{c}G A E_{S P_{-} \text {fluorine }} \\
{[-]}\end{array}$} \\
\hline & $t_{\text {interface_reference }}$ & $t_{\text {interface_fluorine }}$ & $S_{\text {reference }}$ & $S_{\text {fluorine }}$ & & \\
\hline${ }^{63} \mathrm{Cu}^{+}$ & $110 \pm 19$ & $180 \pm 2$ & $(1.4 \pm 0.2) \times 10^{-4}$ & $(7.07 \pm 0.04) \times 10^{-2}$ & $(510 \pm 80)$ & $(0.6 \pm 0.2)$ \\
\hline${ }^{90} \mathrm{Zr}^{+}$ & $357 \pm 13$ & $155 \pm 3$ & $(9.2 \pm 0.2) \times 10^{-3}$ & $(6.75 \pm 0.08) \times 10^{-3}$ & $(0.73 \pm 0.03)$ & $(2.3 \pm 0.2)$ \\
\hline${ }^{107} \mathrm{Ag}^{+}$ & $293 \pm 26$ & $137 \pm 4$ & $(9.7 \pm 0.4) \times 10^{-5}$ & $(3.43 \pm 0.05) \times 10^{-2}$ & $(350 \pm 20)$ & $(2.1 \pm 0.3)$ \\
\hline${ }^{184} \mathrm{~W}^{+}$ & $41 \pm 2$ & $18 \pm 1$ & $(1.77 \pm 0.06) \times 10^{-4}$ & $(2.97 \pm 0.03) \times 10^{-5}$ & $(0.170 \pm 0.008)$ & $(2.3 \pm 0.3)$ \\
\hline
\end{tabular}

the ${ }^{63} \mathrm{Cu}^{+}$signal by a factor of 400 considering the central part of the thin film (in Figure 3 a1, frame 60 and frame 100 for the experiments without and with the fluorine gas, respectively) and increased the ${ }^{28} \mathrm{Si}^{+}$signal 174 times (analogically, frame 200 and frame 100 in Figure 3 a2). Figure 3 b1 presents the results of the $\mathrm{Zr}$ layer. The sputtering process is enhanced by the fluorine gas and the layer is milled more than twice faster although the ${ }^{90} \mathrm{Zr}^{+}$ionization is less efficient (almost 1.5 times lower). Here, ${ }^{28} \mathrm{Si}^{+}$signal has increased by a factor of 158 when comparing to the measurement without the fluorine gas. This also means the advantage of $\mathrm{Zr}$ over $\mathrm{Cu}$ when affecting Si secondary ion yields. An unprecedented, over 1000 times higher (when comparing the Reference signal at frame 150 with the averaged signal obtained with the fluorine gas at frame 57) ${ }^{107} \mathrm{Ag}^{+}$signal record in the central part of the film was achieved due to the fluorine gas supply. Also the ${ }^{28} \mathrm{Si}^{+}$ signal was increased by a factor of 142 . In contrast to all previously analysed samples, the fluorine gas has negatively impacted the ionization process of ${ }^{184} \mathrm{~W}^{+}$damping the secondary ion signal measured with TOF-SIMS more than three times in the case of peak values. In addition, the ${ }^{28} \mathrm{Si}^{+}$signal enhancement was much lower than previously (only up to 8 times higher).

In comparison with the depth profiles measured with the water vapour (in particular Figure S2 a2 and c2), in the case of experiments with fluorine no specific surface-only effects (such as a sudden signal increase within the first several acquired frames) were observed. Moreover, it seems that in the case of $\mathrm{Cu}$ and $\mathrm{Ag}$, surface oxidation (visible in Figure S3 a1 and $\mathrm{c} 1$ in Supporting Information) seems to hamper the ion yield enhancing effect of fluorine in the initial stage of the sample sputtering process. For all considered elements, the collected data suggest that adding fluorine gas during a TOFSIMS depth profile measurement allows for better recognition on interface between a thin film and a substrate (Figure S3) which is not the case when supplying the water vapour (Figure S2). Due to the shape of secondary ion distributions, i.e. a drastic signal drop in the case of metallic thin film elements and a sudden sharp ${ }^{28} \mathrm{Si}^{+}$substrate signal increase, this can be achieved using any single elemental signal of the sample (regardless if a major thin film element or a substrate element is considered).

Table 2 summarizes the TOF-SIMS signals integrated over the thin film thickness which were acquired with and without the presence of the fluorine gas. Following the tendency observed during the tests with the water vapour, the highest ionization enhancement was achieved in the case of ${ }^{63} \mathrm{Cu}^{+}$and ${ }^{107} \mathrm{Ag}^{+}$(by a factor 510 and 350, respectively, therefore around 50 times better than when exposing those materials to the water vapour). Still ${ }^{90} \mathrm{Zr}^{+}$signal was damped by the supplementary gas but less than previously ( 0.73 versus 0.18 ). Finally, in the case of ${ }^{184} \mathrm{~W}^{+}$signal, a reverse response to the fluorine gas was observed when comparing to the effect of water. Instead of increasing the secondary ion signal, here the fluorine has caused a decrease by factor of 0.17 . Although in TOF-SIMS community an application of fluorine- based primary beam (i.e. $\mathrm{SF}_{5}{ }^{+52-55}$ ) as well as $\mathrm{SF}_{6}$ plasma treatment ${ }^{56}$ are commonly known, no literature has reported a fluorine-gas-assisted FIB-TOF-SIMS elemental characterization. Therefore, the values of $G A E_{\text {TOF-SIMS_fluorine }}$ for $\mathrm{Cu}, \mathrm{Zr}, \mathrm{Ag}$ and $\mathrm{W}$ given in Table 2 are published for the first time.

Similarly as in the case of water vapour, the presence of $\mathrm{Xe}_{2} \mathrm{~F}$ gas during the FIB sputtering results in the formation of reactive fluorine radicals. Due to the interactions with the sample metals, metal fluoride compounds are produced following the general formula:

$$
M^{x}+X e F_{2} \stackrel{F I B}{\longrightarrow} M F_{x}+X e .
$$

Among the metals considered in this work (i.e. $\mathrm{Cu}, \mathrm{Zr}, \mathrm{Ag}$ and $\mathrm{W}$ ), only results of $\mathrm{W}$ were documented in the literature ${ }^{57}$ regarding the gas enhancement factor for sputtering rates (with $\mathrm{Ga}^{+}$FIB). For a FIB pixel dwell time of $16 \mu$ s the authors indicate the etch enhancement by a factor of 15 . In our studies an etch enhancement by only a factor of 2.3 was observed, however, this is attributed to different experimental conditions, i.e. $2.7 \mathrm{mbar}$ local pressure (we used $6 \cdot 10^{-3} \mathrm{mbar}$ local pressure). To our best knowledge, the application of $\mathrm{XeF}_{2}$ for increasing etching rates of $\mathrm{Cu}, \mathrm{Zr}$ and $\mathrm{Ag}$ has never been reported before and the results that we present in Table 2 are the first published values. Regarding the use of halogens for increasing FIB milling rates of the $\mathrm{Cu}$ sample, only studies with the mixture of $\mathrm{Cl}+\mathrm{NH}_{3}$ is known ${ }^{58}$. In this case the enhancement between 6 and 12 was achieved. In our studies, the coinjection of $\mathrm{XeF}_{2}$, the Ga FIB sputtering was slowed down by almost $40 \%$. For all other samples ( $\mathrm{Zr}$, Ag and $\mathrm{W}$ ) the process efficiency was increased by a factor of over 2 . This is particularly interesting in the case of zirconium and silver fluorine compounds as they are not volatile. This can indicate reduced binding energies as a driving mechanism for the sputter rate enhancement. 


\section{Influence of fluorine quantity on $\mathrm{Zr}$ ionization and milling time}

In the FIB-related sample processing (such as preparing cross-sections or fabricating microstructures), the standard procedure of using GIS is to localize a gas nozzle very close to the sample surface so that the etching effect of the supplementary gas is maximized. However, this is not necessarily the case regarding a TOF-SIMS analysis. Various studies 28-30 show that the highest ionization probability occurs under very strict conditions and an excess of an ion yield enhancing agent can lead to a decrease of sample secondary ion signals. Therefore, we have investigated the influence of fluorine gas on $\mathrm{Zr}$ sample as a function of the GIS position with respect to the sample surface (Figure S4 in Supporting Information). This sample was chosen because among other samples studied in this work, Zr gives the steadiest in time secondary ion signal. Regarding the choice of the gas, fluorine has seemed to be a better candidate than water vapour as it has caused a lower $\mathrm{Zr}$

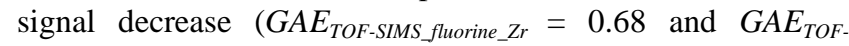
SIMS_water_Zr $=0.18)$ and has sputtered the $\mathrm{Zr}$ thin film slower

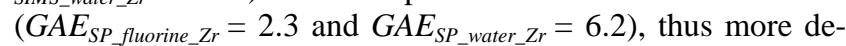
tails can be observed in the depth profile distribution. The ${ }^{90} \mathrm{Zr}^{+}$depth profile (the green line in Figure S4a) measured without fluorine was compared to the data acquired when fluorine GIS was inserted in the proximity of the sample surface (the red line) and to the data obtained when a fluorine valve was open despite the GIS being localized at home position (the blue line). In all cases, a moment of reaching the interface between the $\mathrm{Zr}$ thin film and $\mathrm{Si}$ substrate can be clearly distinguished. When fluorine was injected directly on the sample surface, the material was consumed 2.5 times faster when comparing to a gas-free sputtering (the interface was reached at frame 155 and 380, respectively) and 1.5 times faster when the GIS was at the home position (the interface was crossed around frame 247). Nevertheless, assuming that the GIS nozzle does not affect the ion trajectories or this effect is negligible, in terms of ion yields, and therefore TOF-SIMS analysis, using the reduced amount of fluorine has turned out to be beneficial. Although the ratios of signals measured in the middle of the thin films $S_{\text {fluorine }} / S_{\text {reference }}$ show the same enhancement by the factor of 1.8, the signal integrated over the entire layer thickness is higher by $10 \%$ when the GIS was far away from the sample surface and over 30\% lower when the gas acted directly on it. Thus, it seems that the amount of delivered gas has to be optimized in order to compromise etching speed with conserving the proper $\mathrm{Zr}$ ionization probability.

\section{Error estimations}

As mentioned before, the location of the interface between the thin film and the substrate was obtained from the intersection of the metal secondary ion signal distribution and the substrate secondary signal distribution or (when no distinct signal drop appeared in the metal signal distribution) at $50 \%$ of the ${ }^{28} \mathrm{Si}^{+}$signal. The error of interface location $\Delta t_{\text {interface }}$ (used in Table 1 and Table 2) was estimated based on the lower and upper cross-points of signal envelopes or the signal envelope width, respectively. The error magnitude highly depends on ion yields and thus on the statistics of acquired signals, i.e. low signals with high fluctuations are biased with higher errors. The uncertainty of estimating the location of interfaces (Table 1) introduces the maximum errors of $7.4 \%$ for ${ }^{63} \mathrm{Cu}^{+}$signal, $1.5 \%$ for ${ }^{90} \mathrm{Zr}^{+}$signal, $5.7 \%$ for ${ }^{107} \mathrm{Ag}^{+}$signal and $4.7 \%$ for ${ }^{184} \mathrm{~W}^{+}$signal in the case of reference measurements conducted before the experiments with water vapour. Due to the effect of water vapour, these errors are in general lower (apart from ${ }^{90} \mathrm{Zr}^{+}$for which the error reached 24\%) due to the secondary ion yield enhancement (i.e. 5\%, 4.1\%, $2.9 \%$ for ${ }^{63} \mathrm{Cu}^{+},{ }^{107} \mathrm{Ag}^{+}$and ${ }^{184} \mathrm{~W}^{+}$signals, respectively). The application of fluorine gas (Table 2) has allowed the interface recognition to be achieved with even better precision - the maximum signal errors were $0.5 \%$ for ${ }^{63} \mathrm{Cu}^{+}, 1.2 \%$ for ${ }^{90} \mathrm{Zr}^{+}$, $1.5 \%$ for ${ }^{107} \mathrm{Ag}^{+}$and $0.9 \%$ for ${ }^{184} \mathrm{~W}^{+}$.

The error of gas enhancement factor for ionization $\triangle G A E_{T O F-}$ sIms was calculated using the exact differential:

$$
\begin{gathered}
\Delta G A E_{\text {TOF-SIMS }}=\left|\frac{\partial G A E_{\text {TOF-SIMS }}}{\partial S_{\text {gas }}}\right| \cdot \Delta S_{\text {gas }} \\
+\left|\frac{\partial G A E_{\text {TOF-SIMS }}}{\partial S_{\text {reference }}}\right| \cdot \Delta S_{\text {reference }}
\end{gathered}
$$

Analogically, the error of gas enhancement factor for $\mathrm{Ga}^{+}$ sputter rate, $\triangle G A E_{S P}$, was obtained.

Summary of the gas influence on element ionization and sputtering rates

Figure 4 summarizes the FIB-TOF-SIMS experiments conducted with the water vapour and fluorine gas as a function of atomic mass. Each element has responded individually in terms of ionization probability (Figure 4a), giving ionization probability enhancement for both gas scenarios ( $\mathrm{Cu}$ and $\mathrm{Ag}$ ), a signal decrease $(\mathrm{Zr})$ or giving a slight signal increase when using the water vapour but a signal decrease when using the fluorine gas (W). However, in most cases an increase of sputtering rate was observed in the presence of supplementary gases.

In general, the explanation of ionization probability changes due to the effect of additional gases is not a trivial task even in the case of such simplified model samples (i.e. single-element thin films with reduced impact of the matrix effect) as presented in this publication. The possible scenarios of energy transfers between the primary beam, the analysed specimen and the gas precursor (meaning not only the active element but also other compounds forming the gas delivered by a GIS nozzle) are complex and beyond the scope of these studies. However, the efficiency of modified ionisation probabilities is expected to be correlated with element work functions, ionisation energies and electron affinities. For example, fluorine is the most electronegative (i.e. the most capable to attract an additional electron ${ }^{59}$ ) element in the periodic table with the Pauling electronegativity coefficient $\chi_{\mathrm{F}}=3.98$ and oxygen is the second one with $\chi_{0}=3.44$. This can explain GAE $E_{\text {TOF_SIMS_FIUORINE }}>$

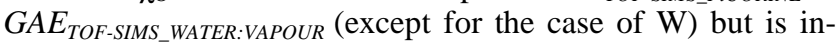
sufficient to answer the question why both of these factors are smaller than 1 in the case of $\mathrm{W}$.

All four samples from the dedicated sample set (one set for studies with water vapour and the other one for studies with fluorine gas) were introduced to the analytical chamber at the same time (meaning the same quality of the primary ion 

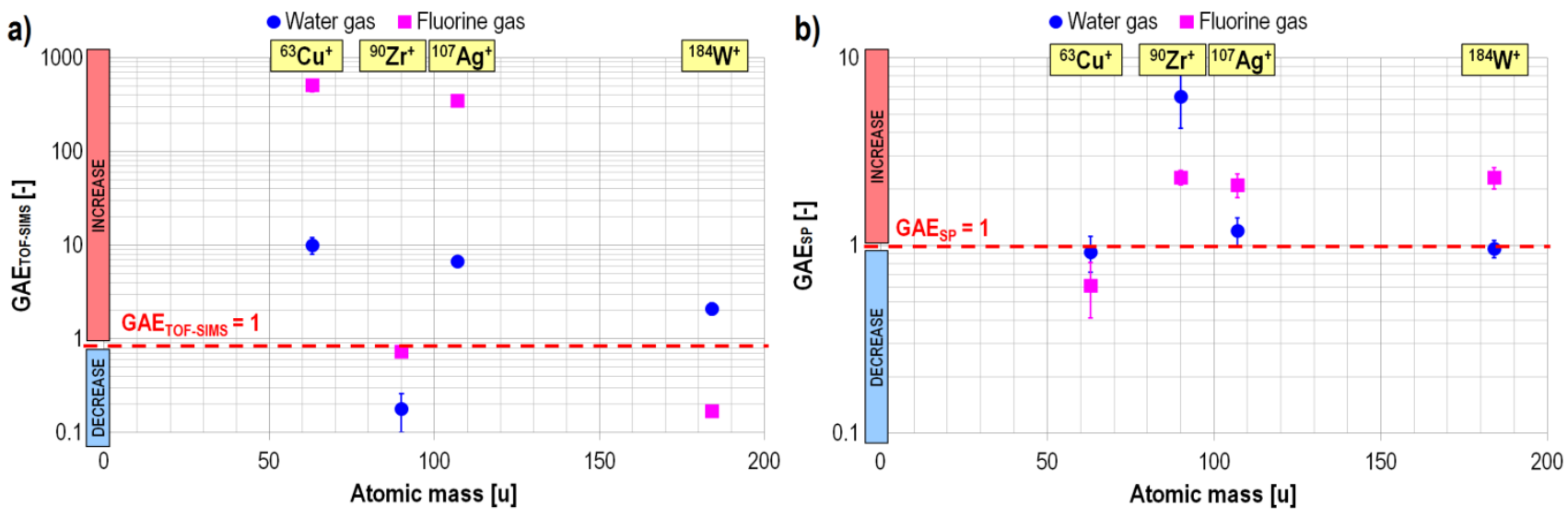

Figure 4. Summary of TOF-SIMS experiments (based on Table 1 and Table 2) conducted with the presence of supplementary gases water (blue dots) and fluorine (pink rectangles): a) the gas enhancement factor for TOF-SIMS signal, b) the gas enhancement factor for sputtering rate.

Table 3. Sputter yields of metals obtained with $20 \mathrm{keV}$ ${ }^{69} \mathrm{Ga}^{+}$ions at standard vacuum conditions, with the presence of water vapour and fluorine gas. The error of $5 \%$ was assumed for the measurement of thin film thickness.

\begin{tabular}{|c|c|c|c|c|c|}
\hline & $\mathrm{Cu}$ & $\mathrm{Zr}$ & $\mathrm{Ag}$ & W \\
\hline \multicolumn{2}{|c|}{$\begin{array}{l}\text { Thin film thick- } \\
\text { ness [nm] }\end{array}$} & $119 \pm 6$ & $143 \pm 8$ & $213 \pm 11$ & $74 \pm 4$ \\
\hline \multirow{3}{*}{ 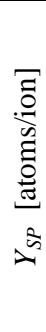 } & $\begin{array}{l}\text { Standard } \\
\text { vacuum }\end{array}$ & $2.5 \pm 0.2$ & $0.5 \pm 0.1$ & $1.6 \pm 0.1$ & $3.8 \pm 0.1$ \\
\hline & $\begin{array}{l}\text { With } \\
\text { water } \\
\text { vapour }\end{array}$ & $2.0 \pm 0.1$ & $2.9 \pm 0.3$ & $1.6 \pm 0.1$ & $3.3 \pm 0.1$ \\
\hline & $\begin{array}{c}\text { With } \\
\text { fluorine } \\
\text { gas }\end{array}$ & $1.5 \pm 0.1$ & $1.4 \pm 0.1$ & $3.1 \pm 0.1$ & $9.0 \pm 0.1$ \\
\hline \multicolumn{2}{|r|}{ 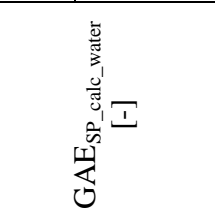 } & $0.8 \pm 0.2$ & $5.80 \pm 0.06$ & $1.0 \pm 0.2$ & $0.87 \pm 0.07$ \\
\hline \multicolumn{2}{|r|}{ 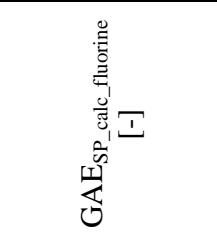 } & $0.6 \pm 0.3$ & $2.8 \pm 0.1$ & $1.94 \pm 0.05$ & $2.37 \pm 0.02$ \\
\hline
\end{tabular}

source, the same level of vacuum chamber purity, the same prior time for potential oxidation etc.).

Also all experiments were conducted at roughly the same chamber pressure and same experimental conditions. The only difference was the absence or presence of the supplementary gas. Therefore, the observed changes of the TOF-SIMS signals result directly from the gas-induced changes of element ionization probabilities and are rather not affected by any other mechanisms.
Sputter yields of metals, $Y_{S P}$, at standard vacuum conditions, in the presence of water vapour and fluorine gas are useful for the FIB community and are summarized in Table 3. These parameters are defined as a number of atoms ejected from a target by an impacting ion ${ }^{60}$ and were obtained using the volume of the sputtered material and the primary ion dose needed to reach a thin film-substrate interface ${ }^{17}$. The knowledge of sputter yields allows a calculated gas enhance-

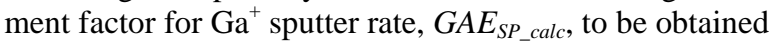

$$
G A E_{S P_{-} \text {calc }}=\frac{Y_{\text {gas }}}{Y_{\text {reference }}} \text {. }
$$

where $Y_{\text {gas }}$ is a calculated sputter yield for the gas assisted experiment and $Y_{\text {reference }}$ is a sputter yield for the experiment conducted at standard vacuum conditions. The values of $G A E_{S P \text { calc water }}$ and $G A E_{S P \text { calc fluorine }}$ given in Table 3 are consistent with $G A E_{S P_{\text {_water }}}$ and $G A E_{S P \text { fluorine }}$ values given in Table 1 and Table 2, respectively.

The sputter rates can be compared to the experimental results obtained with $30 \mathrm{keV} \mathrm{Ga}^{+}$ions by Orloff et al. ${ }^{61}$. Cu sputter rates are comparable while $\mathrm{W}$ and $\mathrm{Zr}$ sputter rates differ by a factor of 3.5 and 5, respectively (Ag sputter rate is not reported). It is worth noticing that SRIM ${ }^{62-64}$ simulations for $\mathrm{Cu}, \mathrm{Ag}$ and $\mathrm{Zr}$ (preformed for the standard vacuum conditions) are not consistent neither with our experimental values nor with results of Orloff for $\mathrm{Cu}$ and $\mathrm{W}$.

Sample topology during FIB-TOF-SIMS measurements with supplementary gases

One of the major benefits of using the TOF integrated within a FIB/SEM instrument is a possibility of monitoring a sample surface before and after elemental characterization. First of all, it allows for verifying the influence of sample topology on secondary ion distributions and recognizing artefacts originating from the surface roughness (including effects of grains and cracks). Moreover, based on a post-FIB-TOF-SIMS crater shape, the adjustment of primary ion beam parameters (the focus, stigmatism in $x$ - and $y$-planes as well as beam centring in $x$ - and $y$-planes) can be verified. Potential material redeposition on crater edges can be also studied as well as FIB induced formation of crater bottom roughness. The latter one 
can particularly affect obtained 3D elemental representation of an investigated specimen.

Figure S5 (in Supporting Information) shows the SEM images of all sample surfaces before and after FIB-TOF-SIMS measurements conducted without and with the presence of water vapour or fluorine gas. Pristine sample surfaces are flat and only in the case of Ag certain precipitations/dirt are observed. The materials exhibit different response to ${ }^{69} \mathrm{Ga}^{+}$ion bombardment which results in different patterns visible on the crater bottoms ( $2^{\text {nd }}$ row of images). $\mathrm{Cu}$ does not seem to be sputtered uniformly (most likely due to the polycrystallinity ${ }^{65}$ ) resulting in the presence of $\mathrm{Cu}$ within the ROI. Minor material re-deposition appears on crater edges of all samples apart from $\mathrm{Zr}$ which seems to be milled in a very clean way. Addition of water vapour ( $3^{\text {rd }}$ row of images) during the FIB sputtering does not modify the shape of formed craters. Only in the case of $\mathrm{W}$ sample brighter dots have occurred on the crater bottom that can indicate material contrast. However, significant influence of fluorine gas on the post-FIB-TOF-SIMS measurements was observed for all samples. 3D structures have built up in the vicinity of crater walls in the case of $\mathrm{Cu}$ and $\mathrm{Ag}$ (this trend was obtained during all six measurements, i.e. three experiments for $\mathrm{Cu}$ and three others for $\mathrm{Ag}$ ) but not in the case of $\mathrm{Zr}$ and W. Nevertheless, for the latter ones, the entire shape of the craters was distorted - the crater edges look bent and wavy and, in addition, a certain slope of the crater bottoms has appeared after the experiments. The modification (flattening) of crater structure in the case of $\mathrm{W}$ was also observed in ${ }^{57}$. The changes of crater shapes rather do not result from the sample charging during the measurements as all elemental maps (both in the lateral plane and in depth) represent uniform TOF-SIMS signals. Modifications of imposed (when defining acquisition parameters) crater dimensions (ROIs) confirm the restriction of limiting the TOF-SIMS data analysis region only to the central part of the evaporated volume.

\section{CONCLUSIONS}

Injecting supplementary gases during TOF-SIMS analysis can strongly affect the efficiency of the element ionization. Nevertheless, the type of the response, i.e. the secondary ion signal enhancement or damping, is very element-specific. Moreover, the situation becomes much more complex when more than one sample element is involved in that process due to the matrix-effect that, in this work, was observed in ${ }^{28} \mathrm{Si}^{+}$ depth profiles. Both, the distribution shape and the signal intensity were affected by the thin film material ions. A sample surface oxidation in general results in increased secondary ion signals within first sputtered frames. However, it has turned out to hamper the ionization process efficiency when the fluorine gas was used during the ${ }^{69} \mathrm{Ga}^{+}$FIB sputtering. Our studies show that a type and a quantity of a supplementary gas have to be carefully adjusted with respect to the material composition as well as a type of analysis, i.e. 2D imaging or 3D elemental representation, since too fast material consumption can decrease the data resolution. On the other hand, in the case of elements which sputter rate is low, application of GIS can be a significant solution allowing for decreasing experiment duration and therefore preventing FIB time dependent instabilities.
In addition, these studies have shown that $\mathrm{Zr}$ gives a very long and stable in time signal. Therefore, this material can be considered as a potential candidate to be used as a TOF-SIMS reference sample. This can help setting the TOF ion extraction optics leading to the best detection limits.

In summary, a synergy of simultaneous use of TOF and GIS within FIB-SEM is expected to improve the efficiency and quality of chemical characterization of materials. Enhanced gas-induced secondary ion yields lead to higher signal-tonoise ratios and therefore have potential for providing higher spatial resolution of elemental distributions measured with TOF-SIMS. Nevertheless more systematic studies are needed to acquire knowledge required for finding the most optimal measurement parameters.

\section{ASSOCIATED CONTENT}

\section{Supporting Information}

Table S1. Summary of sample fabrication parameters applied during the PVD process. (.docx file)

Figure S1. GIS simulations results (.docx file)

Figure S2. Normalized to 1 TOF-SIMS depth profiles of ${ }^{69} \mathrm{Cu}^{+}$, ${ }^{90} \mathrm{Zr}^{+},{ }^{107} \mathrm{Ag}^{+}$and ${ }^{184} \mathrm{~W}^{+}$acquired without (a1-d1) and with (a2-d2) the presence of water vapour. (.docx file)

Figure S3. Normalized to 1 TOF-SIMS depth profiles of ${ }^{69} \mathrm{Cu}^{+}$, ${ }^{90} \mathrm{Zr}^{+},{ }^{107} \mathrm{Ag}^{+}$and ${ }^{184} \mathrm{~W}^{+}$acquired without (a1-d1) and with (a2-d2) the presence of fluorine. (.docx file)

Figure S4. Dependency of the fluorine GIS nozzle position, and therefore the amount of gas delivered to the sample surface, on the ${ }^{90} \mathrm{Zr}^{+}$(a) and ${ }^{28} \mathrm{Si}^{+}$(b) signal magnitude as well as a thin film sputtering process. (.docx file)

Figure S5. SEM images of sample surface before and after FIBTOF-SIMS measurements. (.docx file)

\section{AUTHOR INFORMATION}

\section{Corresponding Author}

* Agnieszka.priebe@empa.ch

\section{Author Contributions}

The manuscript was written through contributions of all authors. / All authors have given approval to the final version of the manuscript.

\section{ACKNOWLEDGMENT}

The EMPAPOSTDOCS-II programme has received funding from the European Union's Horizon 2020 research and innovation programme under the Marie Skłodowska-Curie grant agreement number 754364. The authors would like to express their gratitude to TOFWERK (Thun, Switzerland) for an access to the experimental setup and thank Lex Pillatsch (EMPA and TOFWERK) for the valuable discussion and technical support.

\section{REFERENCES}

(1) Utke, I.; Moshkalev, S.; Russell, P. Nanofabrication Using Focused Ion and Electron Beams: Principles and Applications; Utke, I., Moshkalev, S., Russell, P., Eds.; Oxford University Press: Oxford, 2012.

(2) Wang, Z. M. FIB Nanostructures; Springer: Heidelberg, 2013.

(3) Volkert, C. a; Minor, A. M. F Ocused Ion Beam Micromachining. MRS Bull. 2007, 32 (May), 389-399. 

Beams Instrumentation, Theory, Techniques and Practice; Springer: New York, 2005.

Bleuet, P.; Audoit, G.; Barnes, J.; Bertheau, J.; Dabin, Y.; Dansas, H.; Fabbri, J. Specifications for Hard Condensed Matter Specimens for Three-Dimensional High-Resolution Tomographies. Microsc. Microanal. 2013, 19, 726-739.

Priebe, A.; Audoit, G.; Barnes, J. P. A Novel PFIB Sample Preparation Protocol for Correlative 3D X-Ray CNT and FIBTOF-SIMS Tomography. Ultramicroscopy 2017, 173, 10-13.

(7) Priebe, A.; Goret, G.; Bleuet, P.; Audoit, G.; Laurencin, J.; Barnes, J. P. 3D Correlative Morphological and Elemental Characterization of Materials at the Deep Submicrometre Scale. J. Microsc. 2016, 264 (2), 247-251.

(8) Mayer, J.; Giannuzzi, L. a; Kamino, T.; Michael, J. TEM Sample Preparation and Damage. MRS Bull. 2007, 32 (5), 400407.

(9) Young, R. J.; Cleaver, J. R. A.; Ahmed, H. Characteristics of Gas-Assisted Focused Ion Beam Etching. J. Vac. Sci. Technol. B Microelectron. Nanom. Struct. Process. Meas. Phenom. 1993 11 (2), 234-241.

(10) CaseyJr., H. D.; Doyle, A. F.; Lee, R. G.; Stewart, D. K.; Zimmermann, H. Gas-Assisted Etching with Focused Ion Beam Technology. Science (80-. ). 1994, 24 (1-4), 43-50.

(11) Kwakman, L.; Franz, G.; Taklo, M. M. V.; Klumpp, A.; Ramm, P. Characterization and Failure Analysis of 3D Integrated Systems Using a Novel Plasma-FIB System. AIP Conf. Proc. 2011, 1395 (November), 269-273.

(12) Priebe, A.; Bleuet, P.; Goret, G.; Laurencin, J.; Montinaro, D.; Barnes, J.-P. State-of-the-Art Three-Dimensional Chemical Characterization of Solid Oxide Fuel Cell Using Focused Ion Beam Time-of-Flight Secondary Ion Mass Spectrometry Tomography. Microsc. Microanal. 2016, 22, 1261-1269.

(13) Tomus, D.; Ng, H. P. In Situ Lift-out Dedicated Techniques Using FIB-SEM System for TEM Specimen Preparation. Micron 2013, 44 (1), 115-119.

(14) Ivan, S.; Pillatsch, L.; Utke, I. Direct-Write Milling and Deposition with Noble Gases. In Helium Ion Microscopy; Hlawacek, G., Gölzhäuser, A., Eds.; Springer Cham, 2016; pp 355-393.

(15) Alkemade, P. F. A.; Miro, H. Focused Helium-Ion-BeamInduced Deposition. Appl. Phys. A Mater. Sci. Process. 2014, 117 (4), 1727-1747.

(16) Melngailis, J. Focused Ion Beam Technology and Applications. J. Vac. Sci. Technol. B Microelectron. Nanom. Struct. 2002, 5 (2), 469.

(17) Utke, I.; Hoffmann, P.; Melngailis, J. Gas-Assisted Focused Electron Beam and Ion Beam Processing and Fabrication. J. Vac. Sci. Technol. B Microelectron. Nanom. Struct. 2008, 26 (4), 1197.

(18) Gierak, J. Focused Ion Beam Technology and Ultimate Applications. Semicond. Sci. Technol. 2009, 24 (4).

(19) Matsui, S.; Kometani, R. Three-Dimensional Nanostructure Fabrication by Focused-Ion-Beam Chemical Vapor Deposition and Its Applications. IEICE Trans. Electron. 2007, E90-C (1), 25-35.

(20) Benninghoven, A.; Werner, F. G.; W., R. and H. Secondary Ion Mass Spectrometry-basic Concepts, Instrumental Aspects, Applications and Trends. Surf. Interface Anal. 1987, 10 (8), 435.

(21) Van de Heide, P. Secondary Ion Mass Spectrometry: An Introduction to Principles and Practices; Wiley, 2014.

(22) Sheraz, S.; Barber, A.; Fletcher, J. S.; Lockyer, N. P.; Vickerman, J. C. Enhancing Secondary Ion Yields in ToF-SIMS Using Water Cluster Primary Beams . Supporting Information. Anal Chem 2013, 2-3.

(23) Sheraz, S.; Barber, A.; Razo, I. B.; Fletcher, J. S.; Lockyer, N. P.; Vickerman, J. C. Prospect of Increasing Secondary Ion Yields in ToF-SIMS Using Water Cluster Primary Ion Beams. Surf. Interface Anal. 2014, 46 (S1), 51-53.

(24) Sheraz Née Rabbani, S.; Razo, I. B.; Kohn, T.; Lockyer, N. P.; Vickerman, J. C. Enhancing Ion Yields in Time-of-FlightSecondary Ion Mass Spectrometry: A Comparative Study of Argon and Water Cluster Primary Beams. Anal. Chem. 2015, 87
(4), 2367-2374

Mouhib, T.; Delcorte, A.; Poleunis, C.; Bertrand, P. Organic Secondary Ion Mass Spectrometry: Signal Enhancement by Water Vapor Injection. J. Am. Soc. Mass Spectrom. 2010.

(26) Mouhib, T.; Delcorte, A.; Poleunis, C.; Bertrand, P. Organic Ion Yield Enhancement in Secondary Ion Mass Spectrometry Using Water Vapour Injection. Surf. Interface Anal. 2013, 45 (1), 4649.

(27) Pillatsch, L.; Wirtz, T.; Migeon, H. N.; ScherrerH. SIMS Using Negative Primary Ion Bombardment. Surf. Interface Anal. 2010, 42 (6-7), 645-648.

(28) Graham, W. G. Properties of Alkali Metals Adsorbed onto Metal Surfaces. Proc. Second Int. Symp. Prod. Neutralization Negat. Hydrog. Ions Beams 1980, 126.

(29) Ishikawa, J. Negative Ion Sources. In The Physics and Technology of Ion Sources; Ian G. Brown, Ed.; Wiley-VCH Verlag GmbH \& Co. KGaA, 2005; pp 285-310.

(30) Priebe, A.; Michler, J. Application of a Novel Compact Cs Evaporator Prototype for Enhancing Negative Ion Yields during FIB-TOF-SIMS Analysis in High Vacuum. Ultramicroscopy 2019, 196 (September 2018), 10-17.

(31) Wirtz, T.; Migeon, H. N. In Situ Deposition of Neutral Cs for Secondary Ion Mass Spectrometry. Appl. Surf. Sci. 2004, 222, 186-197.

(32) Niehuis, E.; Grehl, T. ToF-SIMS: Materials Analysis by Mass Spectrometry, 2nd ed.; Vickerman, J. C., Briggs, D., Eds.; IM Publications: Manchester, UK, 2013.

(33) Brison, J.; Houssiau, L. Study of Ionization Processes during TOF-SIMS Analysis by Co-Sputtering Cesium and Xenon. Nucl. Instruments Methods Phys. Res. Sect. B Beam Interact. with Mater. Atoms 2007, 259, 984-988.

(34) Wang, W. H.; Dong, C.; Shek, C. H. Bulk Metallic Glasses. Mater. Sci. Eng. R Reports 2004, 44 (2-3), 45-90.

(35) Löffler, J. F. Bulk Metallic Glasses. Intermetallics 2003, 11 (6), 529-540.

(36) Axinte, E. Metallic Glasses from “ Alchemy” to Pure Science: Present and Future of Design, Processing and Applications of Glassy Metals. Mater. Des. 2012, 35, 518-556.

(37) Wang, W. H. The Elastic Properties, Elastic Models and Elastic Perspectives of Metallic Glasses. Prog. Mater. Sci. 2012, 57 (3), 487-656.

(38) Trexler, M. M.; Thadhani, N. N. Mechanical Properties of Bulk Metallic Glasses. Prog. Mater. Sci. 2010, 55 (8), 759-839.

(39) Sree Harsha, K. S. Principles of Vapor Deposition of Thin Films; Elsevier Ltd, 2006.

(40) Binning, G.; Quate, F.; Gerber, C. Atomic Force Microscope. Phys. Rev. Lett. 1986, 56 (9), 930-933.

(41) Alberts, D.; Von Werra, L.; Oestlund, F.; Rohner, U.; Hohl, M.; Michler, J.; Whitby, J. A. Design and Performance of Two Orthogonal Extraction Time-of-Flight Secondary Ion Mass Spectrometers for Focused Ion Beam Instruments. Instrum. Sci. Technol. 2014, 42 (4), 432-445.

(42) Whitby, J. A.; Östlund, F.; Horvath, P.; Gabureac, M.; Riesterer, J. L.; Utke, I.; Hohl, M.; Sedláček, L.; Jiruše, J.; Friedli, V.; et al. High Spatial Resolution Time-of-Flight Secondary Ion Mass Spectrometry for the Masses: A Novel Orthogonal ToF FIBSIMS Instrument with in Situ AFM. Adv. Mater. Sci. Eng. 2012, 2012, 1-13.

(43) Toth, M.; Lobo, C.; Friedli, V.; Szkudlarek, A.; Utke, I. Continuum Models of Focused Electron Beam Induced Processing. Beilstein J. Nanotechnol. 2015, 6 (1), 1518-1540.

(44) Friedli, V.; Wanzenböck, H. D.; Utke, I. Gas Injection Systems for FEB and FIB Processing: Theory and Experiment. In Nanofabrication using focused ion and electron beams: principles and applications; Utke, I., Moshkalev, S., Russel, P., Eds.; Oxford University Press: New York, 2012; pp 126-183.

(45) Friedli, V.; Utke, I. Optimized Molecule Supply from NozzleBased Gas Injection Systems for Focused Electron- and IonBeam Induced Deposition and Etching: Simulation and Experiment. J. Phys. D. Appl. Phys. 2009, 42 (12).

(46) Mitra, S. K.; Chacraborty, S. Microfluidics and Nanofluidics Handbook; CRC Press: Boca Raton, 2001.

(47) Hervig, R. L.; Mazdab, F. K.; Williams, P.; Guan, Y.; Huss, G. 
R.; Leshin, L. A. Useful Ion Yields for Cameca IMS $3 f$ and $6 \mathrm{f}$ SIMS: Limits on Quantitative Analysis. Chem. Geol. 2006, 227 (1-2), 83-99.

(48) Pillatsch, L.; Vanhove, N.; Dowsett, D.; Sijbrandij, S.; Notte, J.; Wirtz, T. Study and Optimisation of SIMS Performed with $\mathrm{He}^{+}$ and $\mathrm{Ne}+$ Bombardment. Appl. Surf. Sci. 2013, 282, 908-913.

(49) Pillatsch, L.; Wirtz, T. SIMS Using O -, F -, Cl -, Br - and I Primary Ion Bombardment. Surf. Interface Anal. 2012, 44 (10), 1370-1372.

(50) Dubner, A. D.; Wagner, A. The Role of Gas Adsorption in IonBeam-Induced Deposition of Gold. J. Appl. Phys. 1989, 66 (2), 870-874.

(51) Dubner, A. D.; Wagner, A.; Melngailis, J.; Thompson, C. V. The Role of the Ion-Solid Interaction in Ion-Beam-Induced Deposition of Gold. J. Appl. Phys. 1991, 70 (2), 665-673.

(52) Iltgen, K.; Bendel, C.; Benninghoven, A.; Niehuis, E. Optimized Time-of-Flight Secondary Ion Mass Spectroscopy Depth Profiling with a Dual Beam Technique. J. Vac. Sci. Technol. A Vacuum, Surfaces, Film. 1997, 15 (3), 460-464.

(53) Sodhi, R. N. S. Time-of-Flight Secondary Ion Mass Spectrometry (TOF-SIMS):- Versatility in Chemical and Imaging Surface Analysis. Analyst 2004, 129, 483-487.

(54) Stapel, D.; Benninghoven, A. Application of Atomic and Molecular Primary Ions for TOF-SIMS Analysis of Additive Containing Polymer Surfaces. Appl. Surf. Sci. 2001, 174 (3-4), 261-270.

(55) Winograd, N. The Magic of Cluster SIMS. Anal. Chem. 2005, 77 (7), 142 A-149 A.

(56) Leonard, D.; Bertrand, P.; Khairallah-Abdelnour, Y.; ArefiKhonsari. F.; Amouroux, J. Time-of-Flight Secondary Ion Mass Spectrometry Plasma-Treated Low-Density Polyethylene Films. Surf. Interface Anal. 1995, 23 (February), 467-476.

(57) Kola, R.; Celler, G.; Harriott, L. Roughness Effects During Focused Ion Beam Repair of X-Ray Masks with Polycrystalline Tungsten Absorbers. Mater. Res. Soc. Proc. 1993, 279, 593598.

(58) Edinger, K. Gas Assisted Etching of Copper with Focused Ion Beams. J. Vac. Sci. Technol. B Microelectron. Nanom. Struct. 2002, 17 (6), 3058.

(59) Harrison, R. M.; de Mora, S. J. Introductory Chemistry for the Environmental Sciences, 2nd ed.; Cambridge University Press, 1996.

(60) Madou, M. Fundamentals of Microfabrication: The Science of Miniturization, 2nd ed.; CRC Press LLC: Boca Raton, 2002.

(61) Orloff, Jon; Swanson, L.; Utlaut, M. High Resolution Focused Ion Beams: FIB and Its Applications; Springer US, 2003.

(62) Ziegler, J. F.; Biersack, J. P. The Stopping and Range of Ions in Matter. In reatise on Heavy-Ion Science; D.A., B., Ed.; Springer; boston, MA: Boston, 1985; pp 93-129.

(63) Ziegler, J. F.; Biersack, J. P.; Ziegler, M. D. SRIM, the Stopping and Range of Ions in Matter; Ion Implantation Press, 2008.

(64) Ziegler, J. F.; Ziegler, M. D.; Biersack, J. P. SRIM - The Stopping and Range of Ions in Matter (2010). Nucl. Instruments Methods Phys. Res. Sect. B Beam Interact. with Mater. Atoms 2010, 268 (11-12), 1818-1823.

(65) Xu, X.; Della Ratta, A. D.; Sosonkina, J.; Melngailis, J. Focused Ion Beam Induced Deposition and Ion Milling as a Function of Angle of Ion Incidence. J. Vac. Sci. Technol. B Microelectron. Nanom. Struct. Process. Meas. Phenom. 1992, 10 (6), 26752680. 